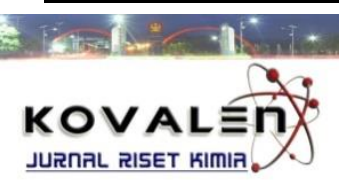

\title{
PENGARUH JENIS ASAM ALAMI TERHADAP PENURUNAN KADAR LOGAM BERAT TIMBAL DALAM DAGING IKAN TERI (Stelophorus indicus Sp) ASAL TELUK PALU
}

\section{[The Effect of Type Natural Acid Against Decline of Content Heavy Metals Plumbum in Meat Anchovy (Stelophorus indicus Sp) Origin Bay Palu]}

\author{
Yulita Nelin Sipa ${ }^{1^{*}}$, Jamaluddin $^{1}, \operatorname{lhwan}^{1}$ \\ 1) Jurusan Farmasi Fakultas MIPA, Universitas Tadulako \\ Jl. Soekarno Hatta, Kampus Bumi Tadulako Tondo Palu, Telp. 0451 - 422611
}

Diterima 22 September 2016, Disetujui 21 November 2016

\begin{abstract}
Research on the effect of type natural acid against decline of content heavy metals plumbum in meat anchovy (Stelophorus indicus Sp) origin bay Palu. The purpose of this study was to determine the best type of acid used in dissolving levels of plumbum as heavy metals for 1 hour immersion and to determine the number of levels of heavy metals of lead that can be dissolved during immersion 1 hour. This study begins with a sample digestion using nitric acid, further qualitative test reagents dithizon $0.005 \%$ (positive), potassium iodide (positive) and sodium carbonate (postitif). Qualitative results test that showed a positive result then measured in metal content of plumbum using atomic absorption spectrophotometer (AAS) at $\lambda 283.3 \mathrm{~nm}$. Then soaking using tamarind are $5 \%$, acetic acid $10 \%$, the filtrate pineapple $100 \%$, starfruit $100 \%$ and lime $25 \%$ for 1 hour at room temperature, after measuring the metal content of plumbum with atomic absorption spectrophotometer (AAS) in $\lambda$ 283.3. The results show levels of heavy metals plumbum before immersion average of $0.8 \mathrm{mg} / \mathrm{kg}$, the average concentration of heavy metals plumbum after soaking tamarind $5 \%$ amounting to $0.787 \mathrm{mg} / \mathrm{kg}$ (1.64\%), $10 \%$ acetic acid at $0.789 \mathrm{mg} / \mathrm{kg}(1.39 \%)$, pineapple filtrate $100 \%$ of $0.7882 \mathrm{mg} / \mathrm{kg}(1.49 \%)$, starfruit $100 \% 0.789 \mathrm{mg} / \mathrm{kg}(1.39 \%)$ and lime $25 \%$ of $0.7916 \mathrm{mg} / \mathrm{kg}(1.06 \%)$. Thus tamarind $5 \%$ is the best type of acid to reduce levels of plumbum metal in Palu bay anchovy origin.
\end{abstract}

Keywords: Acid, Anchovy (Stelophorus indicus Sp), Content, Plumbum

\section{ABSTRAK}

Telah dilakukan penelitian tentang pengaruh jenis asam terhadap penurunan kadar logam berat timbal dalam daging ikan teri (Stelophorus indicus Sp) asal Teluk Palu. Tujuan Penelitian ini adalah untuk mengetahui jenis asam yang paling baik digunakan dalam melarutkan kadar logam berat timbal selama 1 jam perendaman dan untuk mengetahui jumlah kadar logam berat timbal yang dapat dilarutkan selama perendaman 1 jam. Penelitian ini diawali dengan melakukan destruksi sampel menggunakan asam nitrat, selanjutnya dilakukan uji kualitatif dengan pereaksi dithizon 0,005\% (positif), kalium iodida (positif), dan natrium karbonat (positif). Hasil uji kualitatif yang menunjukkan hasil positif selanjutnya diukur kadar logam timbalnya dengan menggunakan spektrofotometer serapan atom (SSA) pada $\lambda 283,3 \mathrm{~nm}$. Kemudian dilakukan perendaman dengan menggunakan asam jawa $5 \%$, asam cuka $10 \%$, filtrat nanas $100 \%$, belimbing wuluh $100 \%$ dan jeruk nipis $25 \%$ selama 1 jam pada suhu kamar, setelah itu diukur kadar logam timbalnya dengan spektrofotometer serapan atom (SSA) pada $\lambda 283,3$. Diperoleh hasil kadar logam berat timbal sebelum perendaman rata-rata $0,8 \mathrm{mg} / \mathrm{kg}$, rata-rata kadar logam berat timbal sesudah perendaman asam jawa $5 \%$ sebesar 0,787 $\mathrm{mg} / \mathrm{kg}(1,64 \%)$, asam cuka $10 \%$ sebesar $0,789 \mathrm{mg} / \mathrm{kg}(1,39 \%)$, filtrat nanas $100 \%$ sebesar 0,7882 $\mathrm{mg} / \mathrm{kg}(1,49 \%)$, belimbing wuluh $100 \% 0,789 \mathrm{mg} / \mathrm{kg}(1,39 \%)$ dan jeruk nipis $25 \%$ sebesar 0,7916 $\mathrm{mg} / \mathrm{kg}(1,06 \%)$. Dengan demikian asam jawa $5 \%$ merupakan jenis asam yang paling baik dalam menurunkan kadar logam timbal pada ikan teri asal Teluk Palu.

Kata Kunci: Asam, Ikan Teri (Stelophorus indicus Sp), Kadar, Timbal 


\section{LATAR BELAKANG}

Kawasan perairan Teluk Palu memiliki ekosistem pesisir dimana di dalamnya terdapat ekosistem estuaria. Kondisi perairan estuaria Teluk Palu secara umum merupakan kawasan pariwisata di bagian barat dan di bagian timurnya selain kawasan pariwisata juga terdapat tambak penggaraman raya. Aktivitas permukiman, perbengkelan dan aktivitas lain dapat menjadi sumber logam berat dalam perairan Teluk Palu (Melisa, 2012).

Adanya logam berat di perairan akibat pencemaran, berbahaya baik secara langsung terhadap kehidupan organisme, maupun secara tidak langsung terhadap kesehatan manusia. Logam berat, selain mencemari perairan juga akan mengendap pada sedimen dan juga akan terkonsentrasi dalam tubuh makhluk hidup melalui proses bioakumulasi (Darmono, 2001).

Penelitian Ningsih (2015), bahwa kondisi air laut di pantai Talise (lokasi reklamasi) telah mengalami pencemaran oleh logam timbal (Pb). Rata-rata kandungan logam timbal $(\mathrm{Pb})$ di Pantai Talise (lokasi reklamasi) Kota Palu telah mencapai 0,53 - 0,58 mg/L. Keputusan Menteri Lingkungan Hidup No. 51 Tahun 2004 tentang baku mutu air laut untuk organisme laut bahwa kadar Nilai Ambang Batas (NAB) untuk logam $\mathrm{Pb}$ 0,008 mg/L (8 ppm). Karena itu, kadar logam Pb di pantai Talise (lokasi reklamasi) lebih tinggi dari nilai ambang batas (Kemen-LH, 2004).
Menurut penelitian Hasrat (2014) bahwa ikan teri di kawasan Teluk Palu (Taman Ria, muara sungai Palu dan pantai Talise) juga telah dicemari logam berat $\mathrm{Pb}$ dengan nilai cemaran $\mathrm{Pb}$ berturut-turut yaitu $1,989 \mathrm{mg} / \mathrm{kg} ; 2,075 \mathrm{mg} / \mathrm{kg} ; 1,655$ $\mathrm{mg} / \mathrm{kg}$. Tercemarnya perairan, Kota Palu perlu diantisipasi dalam menanggulangi cemaran tersebut. Salah satu cara untuk mengatasi cemaran diperairan dengan menurunkan kadar logam berat yang berada pada hasil perikanan. Penurunan kadar logam berat dapat dilakukan dengan menggunakan larutan asam, larutan asam memiliki kemampuan untuk mengikat logam (chelating agent), salah satu cara yang dilakukan untuk mengurangi logam berat yang ada pada ikan dengan cara merendam menggunakan larutan asam dengan tujuan untuk mengurangi jumlah logam berat (timbal) dalam daging ikan sehingga aman untuk dikonsumsi oleh masyarakat. Perendaman dengan menggunakan asam jawa dengan konsentrasi $5 \%$ dalam 30 menit dapat menurunkan kadar logam timbal (Pb) dalam ikan manyung sebesar 2,465 ppm (23,684\%) (Salamah, 1997).

Standar terbaru SNI 7387:2009 bahwa batas maksimum cemaran logam timbal pada ikan yaitu $0,3 \mathrm{mg} / \mathrm{kg}$ (Badan Standardisasi Nasional, 2009). Berdasarkan informasi tersebut, perlu dilakukan penelitian pengaruh jenis asam terhadap penurunan kadar logam berat timbal $(\mathrm{Pb})$ dalam daging ikan teri (Stelophorus indicus) yang nantinya 
dicemarkan logam berat timbal $(\mathrm{Pb})$ dengan menggunakan metode perendaman selama 1 jam.

\section{METODE PENELITIAN}

\section{Bahan dan Peralatan}

Bahan yang digunakan adalah ikan teri yang berasal dari Teluk Palu, Jeruk Nipis 25\%, Belimbing Wuluh 100\%, Asam Jawa $5 \%$, Filtrat Nanas 100\%, Asam Cuka $10 \%$, Aqua destilata, Aquabidest, $\mathrm{NH}_{4} \mathrm{OH}$ (ammonium hidroksida), KCN (kalium sianida), Larutan Ditizon 0,005\% b/v, KI (kalium iodida), $\mathrm{HNO}_{3}$ (asam nitrat) pekat, $\mathrm{Na}_{2} \mathrm{CO}_{3}$ (natrium karbonat).

Peralatan yang digunakan adalah Spektrofotometer Serapan Atom (AA6800), neraca analitik (OHAUS $\AA$ ), cawan porselin, beaker gelas (PYREX®), blender, labu ukur (PYREX®), gelas ukur (PYREX®), hot plate (pemanas), freezer, pipet tetes, tabung reaksi (PYREX®), wadah polystrene, jaring ikan dan cutter.

\section{Prosedur Penelitian}

\section{Teknik Pengambilan Sampel}

Pengambilan sampel dilakukan dengan menggunakan jaring ikan milik nelayan pada satu titik yaitu pantai Talise. Jenis sampel yang diambil yaitu Ikan Teri (Stelophorus indicus Sp) dengan berat rata-rata 1 - 2 gram dan 0,3 - 0,4 gram, serta ukuran masing-masing $5-6 \mathrm{~cm}$.

\section{Penyiapan Sampel}

Ikan teri dengan berat keselurahan 300 gram dalam kondisi masih utuh, dengan mengambil daging teri dan tulang teri, dihilangkan kepala dan isi perut ikan teri. Kemudian dihaluskan dengan menggunakan blender, sehingga diperoleh berat ikan teri 450 gram.

\section{Destruksi Sampel}

Sampel yang telah diketahui beratnya selanjutnya dimasukkan ke dalam erlenmeyer $250 \mathrm{ml}$, ditambahkan asam nitrat pekat sebanyak $25 \mathrm{ml}$ hingga sampel terendam. Lalu didiamkan selama 24 jam dengan tujuan agar dapat mempercepat proses destruksi yang dilakukan. Setelah 24 jam, sampel didestruksi pada hot plate (pemanas) selama 30 menit hingga sampel berwarna kuning muda jernih dan uap nitrat habis. Kemudian dipindahkan ke dalam labu tentukur $100 \mathrm{ml}$ dan ditepatkan sampai garis tanda dengan aqua destilata, lalu disaring dengan kertas saring Whatman no.42. Larutan hasil destruksi dilanjutkan untuk uji kualitatif dan uji kuantitatif logam $\mathrm{Pb}$ (timbal).

\section{Uji Kualitatif (Fries \& Getrost, 1977)}

Ke dalam tabung reaksi dimasukkan 5 ml larutan sampel, diatur $\mathrm{pH}=7$ dengan penambahan ammonium hidroksida $1 \mathrm{~N}$, dimasukkan kalium sianida, ditambahkan 5 $\mathrm{ml}$ dithizon 0,005\% b/v, dikocok kuat, dibiarkan larutan memisah. Terbentuk warna merah tua berarti sampel mengandung $\mathrm{Pb}$.

Sampel dimasukkan 5,0 $\mathrm{ml}$ ke dalam tabung reaksi, ditambah serbuk $\mathrm{KI}$ akan terbentuk endapan kuning. Sampel 5,0 ml dimasukkan ke dalam tabung reaksi, ditambah serbuk $\mathrm{Na}_{2} \mathrm{CO}_{3}$ akan terbentuk endapan putih. 


\section{Uji Kuantitatif Timbal (Pb) (BPOM} Sulteng, 2016)

Membuat kurva kalibrasi. Dari larutan stok $\mathrm{Pb} 1000$ ppm dibuat larutan baku dengan konsentrasi 20,0;10,0;8,0;4,0; 2,0; dan 1,0 ppm.

Larutan baku standar yang telah dibuat masing-masing diukur serapannya dengan spektrofotometer serapan atom pada panjang gelombang 283,3 nm. Hasilnya diplot sehingga menjadi kurva kalibrasi.

\section{Pengujian Sampel}

Hasil dari uji kualitatif yang menunjukkan hasil positif selanjutnya diukur kadar logam timbalnya dengan spektrofotometer serapan atom. Dilakukan perendaman dengan menggunakan larutan asam selama satu jam pada suhu ruang, setelah itu diukur kembali kadar logam timbalnya dengan menggunakan spektrofotometer serapan atom. Pengulangan dilakukan sebanyak satu kali. Konsentrasi timbal $(\mathrm{Pb})$ dalam sampel ditentukan berdasarkan persamaan linier dari kurva kalibrasi sebagai berikut :

$$
y=b x+a
$$

Dimana: $x=$ Konsentrasi larutan

$$
\begin{gathered}
\text { standar } \mathrm{Pb} \\
\mathrm{y}=\text { Absorbansi }
\end{gathered}
$$

\section{Analisis Data (Armanda, 2009)}

Data yang diperoleh dari hasil pengukuran, dimasukan kepersamaan sebagai berikut:

\author{
Kadar logam $\mathrm{Pb}(\mathrm{mg} / \mathrm{kg})=$ \\ (konsentrasi logam $(\mathrm{mcg} / \mathrm{ml}) \times 10^{-3} \times$ volume
}

$$
\text { Berat sampel (gr) } \times 10^{-3}
$$

\section{HASIL DAN PEMBAHASAN}

Hasil uji kualitatif: (1). Positif $\mathrm{Pb}$ dengan menggunakan pereaksi dithizon $0,005 \%$ b/v. (2). Positif $\mathrm{Pb}$ dengan menggunakan pereaksi KI. (3). Positif $\mathrm{Pb}$ dengan menggunakan pereaksi $\mathrm{Na}_{2} \mathrm{CO}_{3}$ (Tabel 1).

Berdasarkan uji kualitatif diatas, maka sampel dinyatakan positif mengandung logam $\mathrm{Pb}$. Sehingga dilanjutkan dengan uji kuantitatif dengan spektrofotometer Serapan Atom pada panjang gelombang $\lambda$ 283,3 $\mathrm{nm}$ diperoleh kadar rata-rata logam $\mathrm{Pb}$ pada ikan $0,8 \mathrm{mg} / \mathrm{kg}$. Hasil yang diperoleh melebihi batas SNI yaitu 0,3 $\mathrm{mg} / \mathrm{kg}$. Jika jumlah timbal yang diserap oleh tubuh melampaui batas SNI yaitu 0,3 $\mathrm{mg} / \mathrm{kg}$, maka akan berdampak keracunan terhadap banyak organ yang terdapat dalam tubuh (Palar, 2004). Untuk mengatasi itu semua, perlu dilakukan penurunan kadar logam $\mathrm{Pb}$ pada ikan dengan menggunakan jenis asam, penurunan kadar logam $\mathrm{Pb}$ dapat dilakukan dengan perendaman asam selama 1 jam pada suhu ruang.

Perendaman dengan larutan asam dapat mengikat logam oleh asam - asam organik yang terkandung didalam larutan asam yaitu asam sitrat, asam askorbat, asam malat, asam format, dan asam oksalat. Selain itu, asam sitrat dapat mengikat ion-ion logam dalam pengkhelatan (Layani, 2010).

Berdasarkan penelitian yang dilakukan, kemampuan asam jawa 5\% dapat melarutkan logam $\mathrm{Pb}$ sebesar 
$1,625 \%$, sementara dengan asam cuka $10 \%$, filtrat nanas $100 \%$, belimbing wuluh $100 \%$ dan jeruk nipis $25 \%$ yang tingkat konsentrasi keasamannya lebih tinggi mampu melarutkan $\mathrm{Pb}$ walaupun tidak sampai batas SNI yaitu $0,3 \mathrm{mg} / \mathrm{kg}$ (Tabel 2).

Tabel 1. Hasil Uji Kualitatif Logam Pb

\begin{tabular}{|c|c|c|c|c|c|c|}
\hline No. & Logam & $\mathrm{PH}$ & $\begin{array}{l}\text { Reaksi } \\
\text { dengan } \\
\text { larutan }\end{array}$ & $\begin{array}{l}\text { Hasil Teori } \\
\text { (Fries \& } \\
\text { Getrost, 1977) }\end{array}$ & Hasil Penelitian & Keterangan \\
\hline 1 & $\mathrm{~Pb}$ & 7 & Dithizon 0,005 & $\begin{array}{c}\text { Terbentuk } \\
\text { warna merah } \\
\text { tua }\end{array}$ & $\begin{array}{c}\text { Terbentuk } \\
\text { warna merah } \\
\text { tua }\end{array}$ & + \\
\hline 2 & $\mathrm{~Pb}$ & - & Kalium lodida & $\begin{array}{c}\text { Terbentuk } \\
\text { endapan } \\
\text { kuning }\end{array}$ & $\begin{array}{c}\text { Terbentuk } \\
\text { endapan } \\
\text { kuning }\end{array}$ & + \\
\hline 3 & $\mathrm{~Pb}$ & - & $\begin{array}{c}\text { Natrium } \\
\text { Karbonat }\end{array}$ & $\begin{array}{c}\text { Terbentuk } \\
\text { endapan putih }\end{array}$ & $\begin{array}{c}\text { Terbentuk } \\
\text { endapan putih }\end{array}$ & + \\
\hline
\end{tabular}

Tabel 2. Penurunan kadar logam $\mathrm{Pb}$ setelah perendaman dalam larutan asam selama 1 jam

\begin{tabular}{ccccccc}
\hline Kode & $\begin{array}{c}\text { Kadar } \\
\text { Sebelum } \\
\text { Perendaman }\end{array}$ & $\begin{array}{c}\text { Rata-Rata } \\
\text { Kadar } \\
\text { Sebelum } \\
\text { Perendaman }\end{array}$ & $\begin{array}{c}\text { Kadar } \\
\text { Sesudah } \\
\text { Perendaman }\end{array}$ & $\begin{array}{c}\text { Rata-Rata } \\
\text { Kadar } \\
\text { Sesudah } \\
\text { Perendaman }\end{array}$ & $\begin{array}{c}\% \\
\text { Penurunan }\end{array}$ & $\begin{array}{c}\text { Rata-Rata } \\
\% \\
\text { Penurunan }\end{array}$ \\
\hline AJ 5\% (I) & 0,7996 & 0,8 & 0,7868 & & $1,60 \%$ & \\
AJ 5\% (II) & 0,8004 & 0,7872 & 0,787 & $1,65 \%$ & $1,625 \%$ \\
AC 10\% (I) & 0,7996 & & 0,7888 & & $1,35 \%$ & \\
AC 10\% (II) & 0,8004 & 0,8 & 0,7892 & 0,789 & $1,40 \%$ & $1,375 \%$ \\
FN 100\% (I) & 0,7996 & & 0,788 & & $1,45 \%$ & \\
FN 100\%(II) & 0,8004 & 0,8 & 0,7884 & 0,7882 & $1,50 \%$ & $1,475 \%$ \\
BW 100\% (I) & 0,7996 & & 0,7888 & & $1,35 \%$ & \\
BW 100\% (II) & 0,8004 & 0,8 & 0,7892 & 0,789 & $1,40 \%$ & $1,375 \%$ \\
JN 25\% (I) & 0,7996 & & 0,7916 & & $1,00 \%$ & \\
JN 25\%(II) & 0,8004 & 0,8 & 0,7916 & 0,7916 & $1,10 \%$ & $1,05 \%$ \\
\hline
\end{tabular}

Dengan demikian, salah satu cara yang dapat dilakukan oleh masyarakat untuk menurunkan kadar logam dari makanan yang berasal dari laut adalah dengan cara melakukan perendaman terlebih dahulu dalam larutan asam jawa, asam cuka, filtrat nanas, belimbing wuluh dan jeruk nipis. Selain harganya murah dan mudah diperoleh, asam jawa, asam cuka, filtrat nanas, belimbing wuluh dan jeruk nipis, yang mengandung berbagai macam senyawa organik ini terbukti dapat menurunkan kadar logam berat timbal yang terdapat dalam ikan.

\section{KESIMPULAN}

Berdasarkan hasil penelitian yang diperoleh, maka dapat disimpulkan bahwa asam jawa 5\% merupakan jenis asam yang paling baik digunakan dalam melarutkan 
logam berat timbal $(\mathrm{Pb})$ selama 1 jam perendaman pada ikan teri asal Teluk Palu.

Pada perendaman selama 1 jam, kadar logam $\mathrm{Pb}$ larut dari $0,8 \mathrm{mg} / \mathrm{kg}$ menjadi $0,7868 \mathrm{mg} / \mathrm{kg}$ (asam jawa $5 \%$ ); $0,7888 \mathrm{mg} / \mathrm{kg}$ (asam cuka 10\%); 0,788 $\mathrm{mg} / \mathrm{kg}$ (filtrat nanas $100 \%$ ); 0,7888 $\mathrm{mg} / \mathrm{kg}$ (belimbing wuluh 100\%); 0,7916 mg/kg (jeruk nipis $25 \%$ ) pada perlakuan pertama, dan untuk perlakuan pengulangan di dapatkan penurunan kadar logam berat $\mathrm{Pb}$ dalam ikan terri asal Teluk Palu yaitu $0,7872 \mathrm{mg} / \mathrm{kg}$ (asam jawa 5\%); 0,7892 $\mathrm{mg} / \mathrm{kg}$ (asam cuka 10\%); 0,7884 mg/kg (filtrat nanas 100\%); 0,7892 $\mathrm{mg} / \mathrm{kg}$ (belimbing wuluh 100\%) dan 0,7916 mg/kg (jeruk nipis 25\%).

\section{UCAPAN TERIMAKASIH}

Ucapan terima kasih penulis
sampaikan kepada pihak Badan Pengawasan Obat dan Makanan (BPOM) Kota Palu Laboratorium Kimia Farmasi FMIPA UNTAD yang telah mengizinkan dan membantu penulis untuk menguji dan menyelesaikan penelitian ini.

\section{DAFTAR PUSTAKA}

Armanda, Firdhany. 2009. Studi Pemanfaatan Buah Jeruk Nipis (Citrus Aurantifolia Swingle) Sebagai Chelator Logam $\mathrm{Pb}$ dan Cd Dalam Udang Windhu. [Skripsi]. Medan: Fakultas Farmasi Universitas Sumatera Utara.

Badan Standarisasi Nasional, 2009, Batas Maksimum Cemaran Logam Berat dalam Pangan. SNI 7387 : 2009.

BPOM Sulteng. 2016. Penetapan Kurva Kalibrasi Logam Berat Pb Pada Produk Pangan. Palu: Sulawesi Tengah.
Darmono. 2001. Lingkungan Hidup Dan Pencemaran, Hubunganya dengan Toksikologi Senyawa Logam. Jakarta: UI-Press.

Fries J,. Getrost H. 1977. Organic Reagents For Trace Analysis. 1st edition. Germany: E Merck darmstadt.

Hasrat. 2014. Analisis Logam Timbal (Pb) Pada Ikan Petek (Leiognathus Sp.) dan Ikan Teri (Stelophorus Sp.) di Kawasan Laut Teluk Palu Secara Spektrofotometri Serapan Atom. Online Jurnal Of Natural Science. 3 (3) : 230-238.

Kementerian Lingkungan Hidup. 2004. Keputusan Menteri Negara Lingkungan Hidup Nomor 51 Tahun 2004 tentang Baku Mutu Air Laut. Jakarta: Kemen-LH RI.

Layani P. N. 2010. Pengaruh Variasi Berat Asam Gelugur (Garcinia Atroviridis, Griff) Terhadap Penurunan Kadar Logam Pb, Cr Dan Cd Pada Perebusan Kerang Bulu (Anadara Antiquata) Dari Perairan Belawan, [Skripsi]. Medan: Fakultas Farmasi Universitas Sumatera Utara.

Melisa A. 2012. Akumulasi Logam Timbal $(P b)$ dalam Ikan Belanak (Liza Melinoptera) yang Hidup di Perairan Muara Sungai Poboya, [Skripsi]. Palu: FKIP Universitas Tadulako.

Ningsih Purnama. 2015. Penetapan Kadar Timbal $(\mathrm{Pb})$ Pada Perairan Talise (Lokasi Reklamasi) Kota Palu. Gravitasi, 14 (2).

Palar, Heryanto, 2004. Pencemaran dan Toksikologi Logam Berat. Jakarta: Rineka Cipta.

Salamah, E., 1997, Upaya Menurunkan Kandungan Timbal (Pb) Ikan Manyung (Arius thalassinus) dan Evaluasi Mutu Jambal Roti yang dihasilkan. Buletin Teknologi Hasil Perikanan. IV(2). 